\title{
To Evaluate the Effect of Vitamin E Therapy on the Oxidative Stress Markers (Nitric Oxide, SOD, Glutathione Peroxidase) \& Vitamin E Levels in Pulmonary Tuberculosis Patients
}

\author{
Rohit John Chaudhary ${ }^{1}$, Bharti Kwatra Uppal ${ }^{2}$ \\ 1,2 Department of Biochemistry, Christian Medical College \& Hospital, Ludhiana, Punjab. India.
}

\section{ABSTRACT}

\section{BACKGROUND}

Severe oxidative stress has been reported in TB patients because of infection associated with malnutrition and poor immunity. Mycobacteria can induce reactive oxygen species (ROS) production by activating phagocytes, and enhanced ROS production may promote tissue injury and inflammation. We wanted to compare the effect of antioxidant administration in the outcome of ATT treatment between the test and the control group.

\section{METHODS}

This perspective study was conducted in the Departments of Biochemistry and Chest Medicine, CMC \& Hospital. Hundred patients (fifty controls and fifty tests) who were diagnosed as pulmonary tuberculosis and started on DOT therapy under RNTCP during this period were included in the study. Each participant in the study was subjected to the following test at the first visit, $2^{\text {nd }}$ month and $6^{\text {th }}$ month follow up (biochemical markers Nitric oxide, SOD, Glutathione Peroxidase and Vitamin E levels). Statistical analysis was done using SPSS version.

\section{RESULTS}

The results were based on four categories (male / female, alcoholic / non-alcoholic, smoker / non-smoker, and younger / older age group). Females had responded better with greater fall in percentage of nitric oxide values (69\%) than males $(64.1 \%)$. The mean of SOD activity $(277.5+/-31.5)$ was more in smokers than non-smokers $(261.3$ $+/$ - 36.0) \& percentage fall of nitric oxide in smokers (65\%) \& non-smokers (67 \%). In alcoholics the percentage fall of nitric oxide $(68.3 \%)$ was higher with more SOD activity (Mean $278.7+/$ - 27.6) than non-alcoholics (Mean $256+/$ - 38.0) indicating a positive correlation of smoking $\&$ alcoholism with tuberculosis. Younger age group responded better with more fall in the percentage of nitric oxide (67\%) \& mean SOD activity $(265.8+/-30.1)$ than older age group.

\section{CONCLUSIONS}

Antioxidant supplementation reduces oxidative stress, improves the effectiveness of ATT therapy, and thus helps in improving the outcome in pulmonary tuberculosis.

\section{KEY WORDS}

Pulmonary TB, ATT (Anti-Tubercular Treatment), Antioxidants \& Free Radicals
Corresponding Author: Dr. Rohit John Chaudhary, Department of Biochemistry, Christian Medical College and Hospital, Ludhiana- 141008, Punjab, India.

E-mail: rohitjchaudhary12388@gmail.com

DOI: 10.14260/jemds/2020/651

How to Cite This Article:

Chaudhary RJ, Uppal BK. To evaluate the effect of vitamin $E$ therapy on the oxidative stress markers (nitric oxide, SOD, glutathione peroxidase) \& vitamin E levels in pulmonary tuberculosis patients. J Evolution Med Dent Sci 2020;9(40):29702975, DOI: 10.14260/jemds/2020/651

Submission 02-07-2020,

Peer Review 28-08-2020

Acceptance 05-09-2020,

Published 05-10-2020.

Copyright (C) 2020 Rohit John Chaudhary, et al. This is an open access article distributed under Creative Commons Attribution License [Attribution 4.0 International (CC $B Y 4.0)]$ 


\section{BACKGROUND}

Tuberculosis is a global public health problem \& is responsible for more than 2 million deaths each year. ${ }^{1}$ Pulmonary tuberculosis is an infectious and contagious disease which apparently develops under conditions of a deficient immunologic response. The immune system requires a wide variety of nutrients to function adequately, and some studies suggest that nutritional supplementation may represent a novel approach for a fast recovery. ${ }^{2}$ Tuberculosis is also associated with various socio-economic factors and often occurs in populations suffering from poverty, poor housing, and economic deprivation. These are the major factors predisposing to poor nutritional status and impaired immune function. 3,4,5 Malnutrition and tuberculosis are both problems of considerable magnitude in most of the underdeveloped regions of the world. Malnutrition may predispose to the development of clinical disease or tuberculosis can contribute to malnutrition6. Before the advent of anti-tuberculosis chemotherapy, a diet rich in calories, proteins, fats, minerals and vitamins were generally considered to be an important, if not essential factor in the treatment of tuberculosis. Nutritional status determines normal health and functioning of the all the systems in the body, including immune system which is responsible for host resistance to various infectious diseases. ${ }^{7}$ Furthermore, the reactivation of latent or previously sub-clinical TB infection is often related to deteriorating nutritional status and this explains the observed increase in the prevalence of TB in association with HIV infection. Thus the effective management of diseases, including $\mathrm{TB}$, therefore requires detailed evaluation of nutritional status, since this can help prevent or modify many complications of diseases and also help in making projections of the interaction of nutritional status on the clinical course of the disease. ${ }^{8}$ Three antioxidants that were significantly reduced in tuberculosis patients are glutathione, ascorbic acid and alpha tocopherol, which are important in regenerating a redox cycle.9.10.11 Thus a combined decrease in these antioxidants may markedLy decrease antioxidant capacity in these patients. Accordingly, the deficiency of these antioxidants may markedLy increase oxidative stress, possibly adversely affecting the immune response and predisposing to drug toxicity. 12

An alarming epidemic of tuberculosis has followed due to the rapid rise in HIV / AIDS cases, particularly in developing countries. Mycobacterium can induce Reactive oxygen species (ROS) by activating phagocytes ${ }^{13.14,15}$ and although an important part of host defence mechanism against mycobacterium, enhanced ROS generation may promote tissue injury and inflammation. This further contributes to immunosupression $16,17,18$, particularly in those with impaired antioxidant capacity, such as HIV infected individual.19,20,21 Reactive oxygen species are highly toxic to all types of cells, but especially to lipids (fat cells) causing peroxidation. This results in damage to cell membrane which promotes lung fibrosis and dysfunction in Pulmonary TB. ${ }^{22}$ Free radicals are thought to play a major role in the aetiology of a wide variety of diseases including atherosclerosis, respiratory tract, and neurodegenerative disease, inflammatory bowel disease, cancer and in aging 23,24 . ROS (Reactive Oxygen Species) has been found to be an important contributing factor to lower the concentration of antioxidants in tuberculosis patients. In fact, the combination of malnutrition leading to decreased "supplementation" of antioxidants and enhanced ROS generation leading to increased utilization of these compounds may represent a pathologic loop, which results in markedly enhanced oxidative stress during tuberculosis infection.

Three of the antioxidants that were significantly found to be reduced in tuberculosis patients are Glutathione, ascorbic acid \& $\alpha$ tocopherol, which are integral components of a regenerating redox cycle. ${ }^{25}$ Accordingly the combined deficiency of these antioxidants markedly increases oxidative stress, possibly adversely affecting the immune response and predisposing to the drug toxicity. Moreover, water soluble antioxidants such as glutathione \& vitamin $\mathrm{C}$, and the lipid soluble vitamin E may act synergistically to protect cells from oxidative stress induced damage. ${ }^{26}$ Also the dietary supplementation of vitamin E can significantly increase the LDL of vitamin E and in turn, confers significant protection against oxidative stress. ${ }^{27}$ Human tissues are protected from the oxidative damage by a variety of mechanisms including small molecular weight antioxidants like vitamin C and E.28 Vitamin $\mathrm{E}$ is one of the major, antioxidant found in the membranes and is found to improve the immune system. Short term vitamin E supplementation is known to improve immune responsiveness. ${ }^{29}$ Reduced levels of vitamin $\mathrm{C}$ and $\mathrm{E}$ are associated with an impaired immune response. ${ }^{30}$ In pulmonary tuberculosis there is increase in several circulating markers of free radical activity, indicating ongoing oxidative stress and decrease in the antioxidant activity which may contribute to lung function abnormalities. ${ }^{31}$ Therefore, the supplementation with vitamins may prove to be beneficial in oxidative stress conditions like tuberculosis, thereby improving the effect of ATT drugs.

\section{METHODS}

This is a one-year prospective interventional study conducted in the Departments of Biochemistry and Chest Medicine, CMC \& Hospital, after obtaining ethical clearance \& taking the consent of the patients. Hundred patients diagnosed of pulmonary tuberculosis were started on DOT's therapy under RNTCP regime in the institution were included in the study. Fifty odd numbers were designated as test group who received Vitamin E (200 mg OD) \& other fifty even numbers were designated as control group (placebo). The patients were followed up at $2^{\text {nd }} \& 6^{\text {th }}$ month after initial visit. The informed consent was taken for patients which were enrolled in the study and then estimated for the various biochemical parameters.

$5 \mathrm{~mL}$ of venous blood was drawn \& collected in EDTA and plain vials for further estimation. The collected samples were separated into plasma, serum and haemolysate for the nitric oxide, superoxide dismutase, glutathione peroxidase and vitamin C estimation. Nitric oxide was measured in plasma using the Griess reaction ${ }^{32}$. This system detects nitrite ion $\left(\mathrm{NO}^{2-}\right)$ in a variety of biological \& experimental liquid matrices such as plasma, urine \& tissue culture medium. 


\section{Reagents (Nitric Oxide)}

1. $0.1 \%$ NED Solution - (N-1-napthylenediamine dihydrochloride)

2. $1 \%$ Sulphamide solution in $5 \%$ Orthophosphoric acid

\section{Working Griess Reagent}

Griess reagent was prepared freshly by adding equal volumes of of reagent 1 and reagent 2 .

\section{Superoxide Dismutase}

Superoxide Dismutase levels were determined in red blood cells (RBC) by colorimetric assay using Ransod kit from Randox which employs reaction between xanthine oxidase and INT to form coloured complex.

Reaction Principle-

$$
\begin{aligned}
& \text { Xanthine } \rightarrow \text { XOD } \rightarrow \text { Uric acid + 02- } \\
& \text { INT } \rightarrow 0^{2-} \rightarrow \text { Formazan dye } \\
& \text { OR } \\
& 02-+02-+2 \mathrm{H}+\rightarrow \text { SOD } \rightarrow 02+\mathrm{H}_{2} \mathrm{O}
\end{aligned}
$$

Sample Preparation - EDTA whole blood $0.5 \mathrm{~mL}$ was centrifuged for $10 \mathrm{mts}$. at $3000 \mathrm{rpm}$ and plasma aspirated. The erythrocytes were washed for 4 times with $3 \mathrm{~mL}$ of $0.9 \% \mathrm{NaCl}$ solution, centrifuging for $10 \mathrm{mts}$. at $3000 \mathrm{rpm}$ after each wash. The washed, centrifuged, erythrocytes were than made up to $2.0 \mathrm{~mL}$ with cold redistilled water, mixed and left to stand at 4 ${ }^{\circ} \mathrm{C}$ for $15 \mathrm{mts}$. The Lysate was diluted with $0.01 \mathrm{~mol} / \mathrm{L}$ of phosphate buffer ( $\mathrm{PH} 7.0$ ), so that percentage inhibition falls between $30 \%$ and $60 \%$. A 25 -fold dilution of lysate was done (10 $\mu \mathrm{L}$ of sample dissolved in $240 \mu \mathrm{L}$ of phosphate buffer).

\section{Alpha Tocopherol (Vitamin E)}

Alpha tocopherol was estimated by colorimetric method using Emmeric Engel reaction of Baker and Frank, 1968. ${ }^{33}$

Principle - Serum tocopherol was measured by its reduction of ferric to ferrous ions which then formed a red complex with $\alpha$, $\alpha$ ' dipyridyl. Tocopherols \& carotenes were first extracted into xylene \& than absorbance read at $460 \mathrm{~nm}$ to measure carotenes. A connection for carotenes made after adding ferric chloride \& reading at $520 \mathrm{~nm}$.

\section{Reagents}

1. Absolute Alcohol, aldehyde Free.

2. Xylene.

3. Alpha, alpha, dipyridyl, $1.2 \mathrm{q} / \mathrm{L}$ in $\mathrm{n}$ propanol.

4. Ferric Chloride solution, $1.20 \mathrm{~g} \mathrm{FeCl}_{3} \cdot 6 \mathrm{H}_{2} \mathrm{O} / \mathrm{L}$ in ethanol. Kept in a brown bottle.

5. Standard solution of DL - alpha tocopherol, $10 \mathrm{mg} / \mathrm{L}$ in ethanol.

\section{Glutathione Peroxidase (GPx)}

Glutathione peroxidase was estimated by Ransel kit of Randox Laboratories. Based on the method of Paglia \& valentine, 1967.
Principle - Glutathione peroxidase (GPx) catalyses the oxidation of glutathione (GSH), by cumene hydro peroxidase. In the presence of glutathione reductase (GR) and NADH, the oxidized Glutathione (GSSG) is immediately converted to the reduced form with a concomitant oxidation of NADPH to $\mathrm{NADP}+$. The decrease in absorbance is measured at $340 \mathrm{~nm}$.

Reaction -

$2 \mathrm{GSH}+\mathrm{ROOH} \rightarrow \mathrm{GPx} \rightarrow \mathrm{ROH}+\mathrm{GSSG}+\mathrm{H}_{2} \mathrm{O}$

$\mathrm{GSSG}+\mathrm{NADPH}+\mathrm{H}^{+} \rightarrow \mathrm{GR} \rightarrow \mathrm{NADP}^{+}+2 \mathrm{GSH}$

\section{Statistical Analysis}

All the collected Data was entered in the computer and analyzed using SPSS version 15. The statistical test used were Independent $\mathrm{T}$ test, repeated Anova analysis, Chi square test.

\section{RESULTS}

Hundred patients were enrolled in the study. All the odd numbers were grouped as "TEST" who were given vitamin E (200 mg OD) along with ATT \& the even numbers were grouped as "CONTROL". The following were the significant outcomes of the study:

1. At the last evaluation (6 months) the percentage increase of SOD activity was more in the males (35\%) (mean $250+$ / - 40.5) as compared to females (28\%) (Mean $247+/$ 46.1 ) in the test group, shows that males responded more with SOD activity in response to stress

2. The percentage decrease of nitric oxide value was more in the non-smoker (66.6\%) group than smokers (65.9\%). It showed that smoking had a positive correlation with Tuberculosis outcome (non-smokers respond better to treatment than smokers) as in (Table 2). This also corroborated with the higher fall in nitric oxide in females as most of the smokers were males.

3. The percentage activity of SOD was more in smoker (38 \%) than non-smokers (35\%), indicating more inflammatory damage in smokers than non-smokers.

4. The mean of Glutathione peroxidase activity was more in the non-smoker group at the end of six months, as compared to the control in the test group. No positive correlation was found with smoking.

5. The percentage increase of vitamin $\mathrm{E}$ was more in Nonsmokers (22\%) as compared to smokers (10 \%), indicating a positive correlation between better responses in non-smoker than smokers.

6. The $\%$ decrease of nitric oxide value was more in the nonalcoholic group (14.7\%) than in alcoholic group (10.0\%) at the end of six-month evaluation, indicating a positive correlation of TB and alcohol.

7. The percentage increase of activity in SOD and glutathione peroxidase was more in the non-alcoholic group $(10.5 \%$ \& $26.0 \%)$ as compared to alcoholic group (10.0 \& 21.0), indicating a positive correlation between alcohol and TB pathogenesis

8. In the age group wise comparison, the younger age group (18 - 39) yrs. showed a significant decrease in the nitric oxide value (\% decrease 66.8 ) as compared to the older 
group (\% decrease is 63.9), indicating a better outcome in younger age group as compared to older age group

9. The \% increase of activity of SOD and Glutathione peroxidase were found to be more in younger age (SOD $37.6 \%$ \& Glutathione Peroxidase $71.2 \%$ ) as compared to older age group (SOD $32.4 \%$ \& Glutathione peroxidase $69.8 \%$ ), indicating a better response in younger age group.

\begin{tabular}{|c|c|c|}
\hline Parameters & Male $(\%)(n=56)$ & Female $(\%)(n=44)$ \\
\hline Nitric Oxide & 64.1 & 69.0 \\
\hline Superoxide Dismutase (SOD) & 38 & 35 \\
\hline Vit. E Levels & 45 & 43.5 \\
\hline Parameters & Smoker (\%) & Non-Smoker (\%) \\
\hline Nitric Oxide & 65 & 66.6 \\
\hline Superoxide Dismutase (SOD) & $\begin{array}{c}38.0 \\
\text { (Mean 277.5+ / - 31.5) }\end{array}$ & $\begin{array}{c}35.038 .0 \\
(\text { Mean } 261.3+/-36.0)\end{array}$ \\
\hline Vit. E Levels & 45.1 & 43.8 \\
\hline Parameters & Alcoholic (\%) & Non-Alcoholic (\%) \\
\hline Nitric Oxide & 40.9 & 44.9 \\
\hline Superoxide Dismutase (SOD) & $\begin{array}{c}36.0 \\
\text { (Mean 278.7+/ - 27.6) }\end{array}$ & $\begin{array}{c}37.4 \\
(\text { Mean 256+/-38.0) }\end{array}$ \\
\hline Vit. E Levels & 45.6 & 43.1 \\
\hline \multicolumn{3}{|c|}{ Table 1. Outcome in Different Categories in Our Study } \\
\hline
\end{tabular}

\begin{tabular}{|c|c|c|c|}
\hline Study & Year & Controls & Test \\
\hline Madhab et al ${ }^{41}$ & 2007 & $32.8 \pm 11.9$ & $47.1 \pm 18.4$ \\
\hline Mohod et $\mathrm{al}^{38}$ & 2011 & $0.19 \pm 0.05$ & $0.60 \pm 0.10$ \\
\hline \multirow[t]{2}{*}{ Akiibinu et $\mathrm{al}^{37}$} & 2011 & $14.9 \pm 9.6$ & $8.4 \pm 7.0$ \\
\hline & Nitric & Oxide $(\mu M / L)$ & \\
\hline Reddy et al ${ }^{42}$ & 2004 & $74.58 \pm 6.1$ & $56.4 \pm 5.5$ \\
\hline Kaur et al ${ }^{43}$ & 2005 & $24.04 \pm 6.87$ & $18.83 \pm 5.1$ \\
\hline \multirow[t]{2}{*}{ Akiibinu et $\mathrm{al}^{37}$} & 2011 & $26.3 \pm 10.0$ & $18.0 \pm 8.0$ \\
\hline & Superoxide & \multicolumn{2}{|l|}{ Dismutase (U / mL) } \\
\hline Madhvi et al $^{44}$ & 2009 & \multicolumn{2}{|l|}{$1.27 \pm 0.10(\mathrm{mg} / \mathrm{dL})$} \\
\hline Madhab et $\mathrm{al}^{41}$ & 2007 & \multicolumn{2}{|c|}{$32.8 \pm 11.9(\mathrm{mg} / \mathrm{dL}) 47.1 \pm 18.4(\mathrm{mg} / \mathrm{dL})$} \\
\hline Pawar et al ${ }^{40}$ & 2011 & \multicolumn{2}{|c|}{$13.62 \pm 7.91(\mathrm{mg} / \mathrm{L}) \quad 7.91 \pm 1.4(\mathrm{mg} / \mathrm{L})$} \\
\hline Johnkennedy et $\mathrm{al}^{39}$ & 2011 & \multicolumn{2}{|c|}{$1.64 \pm 0.41(\mathrm{mg} / \mathrm{dL}) 0.84 \pm 0.31(\mathrm{mg} / \mathrm{dL})$} \\
\hline \multicolumn{4}{|c|}{ Vitamin E (Alpha Tocopherol mg / dL) } \\
\hline \multicolumn{4}{|c|}{ Table 2. Comparable Results from Other Studies } \\
\hline
\end{tabular}
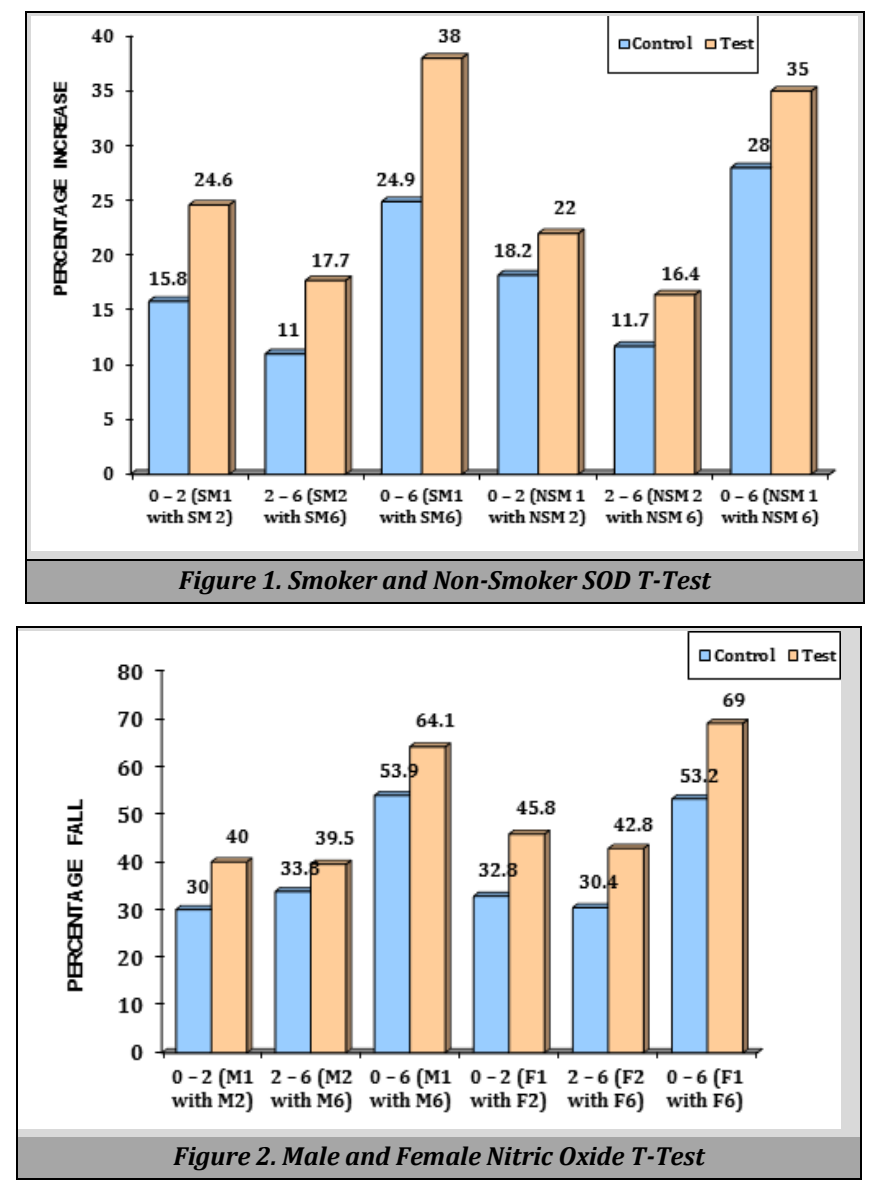

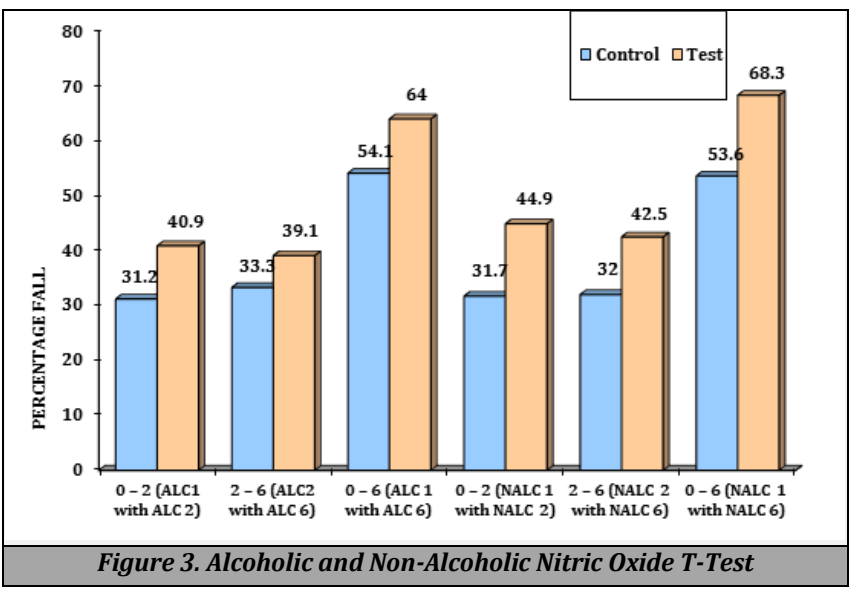

\section{DISCUSSION}

At the end of last evaluation ( 6 months), the percentage increase of SOD activity was more in the males as compared to females in the test group. Males responded more with SOD activity in response to stress (Male $277.8+/$ - 26.0) \& (Female $252.9+/-40.9)$. The mean SOD activity was found to be higher in smokers $(277.5+/-31.4)$ than non-smokers $(261.3+/$ 36.0) indicating SOD as a marker of inflammation. The low SOD activity leads to both oxidative damage \& activation of mediators of inflammation. The average increase in the mean of SOD in test group correlates well with the role of antioxidants in pulmonary inflammation which correlates well with Akiibinu et al. ${ }^{34}$

The statistically significant decrease of nitric oxide value was more in the non-smoker group than smokers indicating that smoking had a positive correlation with Tuberculosis outcome (non-smokers respond better to treatment than smokers) ( $p$ value 0.0 ). This also corroborated with the higher fall in nitric oxide in females as most of the smokers were males in accordance in accordance with Mohod et $\mathrm{al}^{35}$ \& Akiibinu et al. ${ }^{34}$

There is positive correlation of Tuberculosis \& Alcohol, as the percentage fall of Nitric oxide value was more in nonalcoholics (68.3\%) rather than alcoholic (64.0\%) at the end of six-month evaluation, which are in agreement with Mohod et al. ${ }^{35}$ The vitamin $E$ levels were increased in the control group when compared to test, which shows a positive correlation between decrease antioxidant status in pulmonary tuberculosis \& improved status after the treatment.

The percentage increase of vitamin E level was more in non-smokers (45.1) as compared to smokers (43.8), indicating a positive correlation between better responses in nonsmoker than smokers. The younger group $(0.7814+/-0.08)$ showed improved vitamin E levels in the test group than the older age group $(0.7537+/-0.067)$ indicating a decrease antioxidant status in pulmonary Tuberculosis and improved status after treatment. The younger age group responded better to treatment which is in agreement with John Kennedy et $\mathrm{al}^{36}$ \& Pawar et al. ${ }^{37}$ 


\section{CONCLUSIONS}

Pulmonary tuberculosis patients exhibit oxidative stress which is depicted by the change in levels of various markers of oxidative stress (chemical and enzymatic). Along with this, there are decreased levels of non-enzymatic antioxidants (Vitamin E). However, antioxidant (Vitamin E) supplementation for two months as an adjuvant to DOT's therapy not only improves its level, but also the antioxidant status of the pulmonary tuberculosis patients. The results suggest that antioxidant supplementation reduces oxidative stress, improves the effectiveness of ATT therapy and thus helps in improving the outcome in pulmonary tuberculosis. Hence antioxidant supplementation may have a role in faster recovery. Based on the results of our study, large clinical trials are indicated and supplementation with antioxidant vitamins like vitamin $\mathrm{E} /$ vitamin $\mathrm{C}$ as an adjunct to anti-tuberculosis treatment is advisable.

Financial or Other Competing Interests: None.

\section{REFERENCES}

[1] WHO. Treatment of tuberculosis. Guidelines for National programmes. $3^{\text {rd }}$ edn. Geneva: World Health Organization 2003.

[2] Reddy YN, Murthy SV, Krishna DR, et al. Role of free radicals and antioxidants in tuberculosis patients. Indian J Tuberculosis 2004;51(4):213-8.

[3] Macallan D. Malnutrition in tuberculosis. Diagn Microbiol Infect Dis 1999;34(2):153-7.

[4] Cegielski JP, McMurray DN. The relationship between malnutrition and tuberculosis: evidence from studies in human and experimental animals. Int J Tuberc Lung Dis 2004;8(3):286-98.

[5] Leung CC, Yew WW, Tam CM, et al. Socio economic factors and tuberculosis: a district based ecological analysis in Hong Kong. Int J Tuberc Lung Dis 2004;8(8):958-64.

[6] Macallan DC. Malnutrition in tuberculosis. Diagn Microbial Infect Dis 1999;34(2):153-7.

[7] Cegeilski JP, McMurray DN. The relationship between malnutrition and tuberculosis: evidence from the studies in humans and experimental animals. Int J Tuberc Lung Dis 2004;8(3):286-98.

[8] Rosenberg IH. Nutrition and nutritional requirements. In: Isselbacher KJ, Braunwald E, Wilson JD, et al, eds. Harrisons principles and practice of medicine. $13^{\text {th }}$ edn. USA: McGraw-Hill Companies 1994.

[9] Winkler BS, Orselli SM, Rex TS. The redox couple between glutathione and ascorbic acid: a chemical and physiological prospective. Free Radic Biol Med 1994;17(4):333-49.

[10] Meister A. Glutathione-ascorbic acid antioxidant system in animals. J Biol Chem 1994;269(13):9397-400.

[11] Niki E, Noguchi N, Tsuchihashi H, et al. Interactions among vitamin C, vitamin E and beta-carotene. Am J Clin Nutr 1995;65(6 Suppl):1322S-6S.

[12] Walubo A, Smith PJ, Folb PI. Oxidative stress during antituberculous therapy in young and elderly patients. Biomed Environ Sci 1995;8(2):106-13.
[13] May ME, Spagnuolo PJ. Evidence for respiratory burst in the interaction of human neutrophils with Mycobacterium tuberculosis. Infect Immun 1987;55(9):2304-7.

[14] Attwood EM, Weich DJ, Oosthuizen JM. The influence of carbon particles on the concentration of acid phosphatase and lysozyme enzymes within alveolar macrophages during the killing and degradation of Mycobacterium bovis. Tuber Lung Dis 1996;77(4):341-7.

[15] Kuo HP, Ho TC, Wang CH, et al. Increased production of hydrogen peroxide and expression of CD11b/CD18 on alveolar macrophages in patients with active pulmonary tuberculosis. Tuber Lung Dis 1996;77(5):468-75.

[16] Jack CI, Jackson MJ, Hind CR. Circulating markers of free radical activity in patients with pulmonary tuberculosis. Tuber Lung Dis 1994;75(2):132-7.

[17] Grimble RF. Malnutrition and the immune response. Impact of nutrients on cytokine biology in infection. Trans R Sco Trop Med Hyg 1994;88(6):615-9.

[18] Nathan CF, Brukner LH, Silverstein SC, et al. Extracellular cytolysis by activated macrophages and granulocytes. I. Pharmacologic triggering of effector cells and release of hydrogen peroxide. J Exp Med 1979;149(1):84-99.

[19] Favier A. Sappey C, Leclerc P, et al. Antioxidant status and lipid peroxidation in patients infected with HIV. Chem Biol Interact 1994;91(2-3):165-80.

[20] Aukurst P, Muller F. Glutathione redox disturbances in human immunodeficiency virus infection: immunologic and therapeutic consequences. Nutrition 1999;15(2):165-7.

[21] Muller F, Svardal AM, Nordoy I, et al. Virological and immunological effects of antioxidant treatment in patients with HIV infection. Eur J Clin Invest 2000;30(10):905-14.

[22] Vijayamalini M, Manoharan S. Lipid peroxidation, vitamins $\mathrm{C}, \mathrm{E}$ and reduced glutathione levels in patients with pulmonary tuberculosis. Cell Biochem Funct 2004;22(1):19-22.

[23] Witzum JL. The oxidation hypothesis of atherosclerosis. Lancet 1994;344(8925):793-5.

[24] Cross CE, van der Vliet A, Oneill CA, et a. Reactive oxygen species and the lung. Lancet 1994;344(8927):930-3.

[25] Winker BS, Orselli SM, Rex TS. The redox couple between glutathione and ascorbic acid: a chemical and physiological perspective. Free Radic Biol Med 1994;17(4):333-49.

[26] Di Mascio P, Murphy ME, Sies H. Antioxidant defence systems: the role of carotenoids, tocopherols, and the thiols. Am J Clinc Nutr 1991;53(1 Suppl):194S-200S.

[27] Esterbauer H, Gebicki J, Puhl H, et al. The role of lipid peroxidation and antioxidants in oxidative modification of LDL. Free Radic Biol Med 1992;13(4):340-90.

[28] Anderson D. Antioxidant defenses against reactive oxygen species causing genetic and other damage. Mutat Res 1996;350(1):103-8.

[29] Park OJ, Kim HYP, Kim WK, et al. Effect of vitamin E supplementation on antioxidant defense system and humoral immune responses in young, middLe aged and elderly Korean women. J Nutr Sci Vitaminol (Tokyo) 2003;49(2):94-99. 
[30] Chandra RK. 1990 McCollum Award lecture. Nutrition and immunity: lessons from past and new insights into future. Am J Clinc Nutr 1991;53(5):1087-101.

[31] Rai RR, Phadke MS. Plasma oxidant-antioxidant status in different respiratory disorder. Indian J Clin Biochem 2006;21(2):161-4.

[32] Griess P, Bemerkungen zu der abhandLung der HH. Weselsky und Benedikt Ueber einige azoverbindungen. Chem Ber 1879;12:426-8.

[33] Baker H, Frank O. Clinical vitaminlogy: methods and interpretation. Interscience Publishers 1968: p. 172.

[34] Akiibinu MO, Ogunyemi EO, Shoyebo EO. Levels of oxidative metabolites, antioxidants and Neopterin in Nigerian pulmonary tuberculosis. Eur J Gen Med 2011;8(3):213-8.
[35] Mohod K, Dhok A, Kumar S. Status of oxidants and antioxidants in pulmonary tuberculosis with varying bacillary load. Journal of Experimental Sciences 2011;2(6):35-7.

[36] Johnkennedy N, Onyinyechi AS, Chukwunyere NNE. The antioxidant status and lipid peroxidation product of newly diagnosed and six week follow up patients with pulmonary tuberculosis in Owerri, Imo state, Nigeria. Asia Pacific Journal of tropical Disease 2011:292-4.

[37] Pawar BD, Suryakar AN, Khandelwal AS. Effect of micronutrients on oxidative stress and antioxidant status in pulmonary tuberculosis. Biomedical Research 2011;22(4):455-9. 